\title{
DESENVOLVIMENTO SUSTENTÁVEL, REDEFINIÇÃO DO PODER LOCAL E TURISMO COMO ALTERNATIVA DE DESENVOLVIMENTO LOCAL
}

\author{
Julimar Pereira de França \\ Graduado em Ciências Sociais e Professor da Rede Estadual de Ensino do Rio Grande do \\ Norte, Mestre em desenvolvimento e meio ambiente PRODEMA/UERN \\ julimarfranca@hotmail.com \\ Iara Jane de Araújo \\ Curso de turismo da UERN \\ e-mail:janeara@yahoo.com.br
}

\section{RESUMO}

A escassez dos recursos naturais resultante da degradação dos ecossistemas fez emergir a discussão sobre novos paradigmas de desenvolvimento e relacionamento homem/natureza. Nesse sentido, o modelo de desenvolvimento sustentável vem ganhando espaço na agenda Político-administrativa e os poderes locais passaram a incorporar no planejamento do seu desenvolvimento princípios da sustentabilidade.Nesse contexto, a proposta desse trabalho é realizar uma análise sobre as mudanças ocorridas nas últimas décadas nos paradigmas político-administrativo e econômico global e nacional, enfatizando o papel da atividade turística como promotora do desenvolvimento sustentável local no bojo dessas mudanças paradigmáticas.Inicialmente, realizamos um contraponto entre os paradigmas do desenvolvimento tradicional e sustentável,num segundo momento enfatizamos a relação existente entre o paradigma do desenvolvimento sustentável e a descentralização das políticas públicas e por fim abordamos aspectos da relevância do poder local como fomentador de desenvolvimento sustentável local, com base na atividade turística. Por se constituir numa pesquisa bibliográfica, construímos a mesma com base em leituras e produção de fichamentos de referências bibliográficas concernentes as temáticas abordadas. Em suma, percebemos que o turismo se constitui numa viável alternativa de desenvolvimento sustentável local, mas, para isso o novo poder local deve desempenhar o seu papel de fomentador e protagonista do desenvolvimento sócio-econômico da nação.

PALAVRAS-CHAVE: Turismo, desenvolvimento, poder local, descentralização, sustentabilidade.

\section{SUSTAINABLE DEVELOPMENT, REDEFINITION OF LOCAL AND TOURISM AS ALTERNATIVE OF SOCIOECONOMIC DEVELOPMENT}

\begin{abstract}
:
The scarcity of natural resources resulting from the degradation of ecosystems has created a discussion on new paradigms of development and relationship man / nature. Thus, the model of sustainable development is gaining space in the political-administrative and local authorities began to incorporate into their development planning principles sustainability. in this sense, the purpose of this study is to perform an analysis of the changes in recent decades paradigms in the political-administrative and economic global and national levels, emphasizing the role of tourism as a promoter of local sustainable development in the
\end{abstract}


midst of these changes paradigmátics. Initially, we conducted a comparison between the paradigms of traditional and sustainable development, subsequently emphasized the relationship between the paradigm of sustainable development and decentralization of public policies and approach to aspects of the relevance of local developers and local sustainable development based on tourism. Since this is a literature search, we build the same based on readings and production of annotated bibliographic references concerning the topics addressed. In short, we realize that tourism is a viable alternative for local sustainable development, but for that the new local government must play its role as developer and leader of the socio-economic development of the nation.

KEY-WORDS: Tourism, development, local government, decentralization, sustainability 


\section{DESENVOLVIMENTO SUSTENTÁVEL, REDEFINIÇÃO DO PODER LOCAL E TURISMO COMO ALTERNATIVA DE DESENVOLVIMENTO SÓCIO- ECONÔMICO}

\section{INTRODUÇÃO}

As civilizações pré-industriais viviam em harmonia com a biosfera. Na antiguidade, a consciência mitológica predominante levava os homens a uma postura de total dependência em relação ao meio natural. Na Idade Média, apesar da ideologia judaicocristã que concebe o homem como senhor da terra, o saber metafísico-teocêntrico predominante, voltado para especulação espiritual, continuou vislumbrando a natureza como algo obscuro ao conhecimento e a ação transformadora humana. O determinismo natural característico dessas realidades históricas resultava numa atitude de respeito e até de santificação do meio ambiente.

Contudo, no século XVI, a crise do saber medieval e a conseqüente emergência da razão como fundamento do conhecimento provocou profundas transformações na relação sociedade/natureza. O homem moderno começou a fazer uso da razão objetivando conhecer e dominar a natureza transformando-a em face de suas necessidades. Essa ideologia presente no movimento iluminista é notória na afirmação do filósofo Friedrich Engels:

O animal apenas utiliza a natureza, nela produzindo modificações somente por sua presença; o homem a submete, pondo-a a serviço de seus fins determinados, imprimindo-lhe as modificações que julga necessária, isto é, domina a natureza (1979, p.223).

Essas mudanças culminaram no advento do paradigma científico cartesiano-newtoniano que defende o domínio da natureza e o desenvolvimento da ciência e da técnica com o objetivo de melhorar as condições de vida humana. Já no século XVI, o filósofo Francis Bacon afirmava que a filosofia deveria deixar a abstração e se interessar por questões práticas. A técnica científica era vista como um recurso capaz de trazer o progresso material e proporcionar uma melhor qualidade de vida aos homens.

A Revolução Industrial no século XVIII foi um marco da ciência e da técnica e aumentou a crença na idéia de progresso, tendo a partir de então surgido à produção em série e o conseqüente consumo de massa. Essas mudanças permitiram que a satisfação material humana atingisse níveis nunca vistos antes, mas provocaram uma explosão demográfica urbana e a dilapidação dos recursos naturais. Apesar disso, O homem em busca do progresso material se julgava cada vez mais senhor dos recursos naturais do planeta.

No mesmo século, surgiu a ciência econômica, ignorando totalmente a finitude e o valor dos bens naturais. Adam Smith, fundador da economia e todos os demais economistas clássicos, inclusive Karl Marx, afirmavam que a natureza é um bem sem valor, somente após sofrer a ação do trabalho humano e ser transformada é que esta adquire valor de troca.

Nesse sentido, os sistemas econômicos capitalista e socialista que se consolidaram baseados na doutrina econômica clássica e no paradigma industrial se tornaram instituições econômicas predadoras da natureza levando a humanidade à degradação do meio ambiente, 
em conseqüência dos elevados padrões de consumo e do uso sem controle dos recursos naturais. Ademais, após o advento do paradigma econômico clássico o progresso das sociedades humanas tem sido mensurado com base no crescimento econômico (aumento do PIB e da renda per capita), desconsiderando o desenvolvimento em outras dimensões como a social, cultural e, sobretudo ambiental.

Contudo, na segunda metade do século XX, esses modelos sócio-econômicos apresentaram sinais de esgotamento. $\mathrm{O}$ crescimento econômico sem levar em consideração a capacidade de carga do planeta conduziu a humanidade a uma grave crise civilizatória, presente na contestação da sociedade industrial e de consumo e no aumento da consciência sobre o esgotamento dos recursos naturais em escala global. Diante disso, emergiu a discussão sobre novos modelos de desenvolvimento.

\section{O PARADIGMA DO DESENVOLVIMENTO SUSTENTÁVEL}

O célere crescimento econômico pós II guerra parecia tornar praticamente impossível à emergência da discussão em relação aos limites da biosfera, diante do modelo consumista predominante. Apesar disso, no ano de 1962, a bióloga norte-americana Rachel Carson, publicou o livro "primavera silenciosa", alertando sobre os efeitos dos produtos químicos usados na agricultura para a saúde humana e o meio ambiente.

Em 1968, os movimentos de contracultura que surgiram na Europa e se espalharam pelo mundo também criticaram a incompatibilidade existente entre o estilo de vida da sociedade de consumo e a conservação da natureza. Nesse mesmo ano foi criado por iniciativa do industrial italiano Aurélio Peccei e do cientista escocês Alexandre King, o Clube de Roma, objetivando estudar os contrastes existentes entre o paradigma de desenvolvimento predominante e o meio ambiente. No final dessa década também aconteceram às primeiras discussões oficiais sobre esta temática, com a promoção da conferência intergovernamental para uso racional e conservação da biosfera, organizada pela UNESCO (Organização das Nações Unidas para ciência, educação e cultura).

Em 1972, o Clube de Roma produziu um importante relatório sob a coordenação do cientista Norte-americano Dennis Meadows, denominado Os limites do crescimento, em que abordava os principais problemas produzidos pelo modelo econômico vigente para o meio ambiente: crescimento populacional, poluição e esgotamento dos recursos naturais. Esse documento alertava a humanidade para a finitude dos recursos naturais e para a urgência na criação de mecanismos para limitar o crescimento econômico. (CAMARGO, 2003)

Nos anos 70, o debate se ampliou e em 1972, aconteceu em Estocolmo, na Suécia, a I Conferência das nações unidas sobre o desenvolvimento humano. Esta se caracterizou pelas discussões entre países desenvolvidos e subdesenvolvidos sobre desenvolvimento e meio ambiente e deu bastante ênfase aos problemas da pobreza e do crescimento populacional, além de elaborar metas sócio-ambientais para o futuro do planeta. Esse evento é um divisor de águas na preocupação internacional com os problemas ambientais.

Em 1972, também ocorreu um avanço nessa discussão quando o canadense Maurice Strong, criou o conceito de ecodesenvolvimento para caracterizar uma concepção alternativa de desenvolvimento econômico que levasse em consideração a questão ambiental.(CAMARGO.2003) 
Como resultado da conferência de Estocolmo, nesta década surgiram diversas organizações internacionais preocupadas em discutir os problemas ambientais. Em várias partes do mundo também foram criados organismos estatais e leis específicas de meio ambiente. Países como Holanda e Alemanha criaram seus selos ecológicos e os Estados Unidos estimulou a craçãi deleis como a do ar puro e da água pura,além de exigir estudos de impactos ambientais para empreendimento impactantes.

Ainda nos anos 70, a chamada crise do petróleo também contribuiu para que governantes e populações de países do mundo inteiro começassem a questionar a viabilidade dos modelos econômicos diante da escassez do capital natural.

Nos anos 80, permaneceu o consenso global em torno da gravidade dos problemas ambientais e da urgência do ecodesenvolvimento. Para SACHS (1993), esse paradigma do desenvolvimento se realiza por meio de um modelo econômico que compatibilize eficiência econômica, justiça social e prudência ecológica.

Em 1983, a ONU criou a Comissão Mundial Sobre Meio Ambiente e Desenvolvimento. Esse fórum teve como presidente Gro Harlem Brundtland, primeira ministra da Noruega. Após anos de estudos e debates, essa comissão lançou em 1987 o célebre relatório Nosso Futuro Comum ou relatório BRUNDTLAND. Nesse documento surgiu o conceito de desenvolvimento sustentável como:

Um processo de transformação, no qual a exploração dos recursos, a direção dos investimentos, a orientação da evolução tecnológica e a mudança constitucional se harmonizam e reforçam o potencial presente e futuro, a fim de atender as necessidades e aspirações humanas (CMMAD, 1991, p.49)

A partir disso, o termo desenvolvimento sustentável esteve no centro da discussão ambiental no mundo inteiro suscitando muitos debates, controvérsias e questionamentos. Como alcançar o desenvolvimento sustentável no capitalismo? Dá para pensar na satisfação das necessidades das gerações futuras enquanto milhões de seres humanos não satisfazem suas necessidades mais básicas?Como satisfazer as necessidades humanas sem esgotar os recursos naturais?Essas e outras interrogações que surgiram na época permanecem até hoje nas discussões sobre esta temática

Quando comparado com outros documentos anteriores, o relatório Brundtland apresenta um caráter bastante diplomático e um grau enorme de realismo. Por isso o mesmo foi bastante aceito pela comunidade internacional e disseminou o paradigma do desenvolvimento sustentável como o que satisfaz as necessidades do presente sem comprometer a capacidade das gerações futuras satisfazerem suas próprias necessidades.

Mas o paradigma do desenvolvimento sustentável não está restrito à preocupação com a questão ambiental; este é algo dinâmico e comporta diversas dimensões. SACHS (1993) afirma que o planejamento para o desenvolvimento sustentável deve levar em consideração as seguintes dimensões:

a) Sustentabilidade social: que está relacionada com a garantia dos direitos e a distribuição eqüitativa da renda; 

b) Sustentabilidade econômica: diz respeito à alocação eficiente dos recursos e a um fluxo constante de investimentos;
c) Sustentabilidade ecológica: relaciona-se com conservação dos recursos naturais do planeta;
d) Sustentabilidade espacial: Concernente a uma melhor configuração rural-urbana e a uma maior organização na distribuição dos assentamentos humanos;
e) Sustentabilidade cultural: que leva em consideração a modernização e as raízes endógenas desses processos para que aconteçam em sintonia com a cultura local

Na verdade, o grande marco nessa discussão foi a Conferência das Nações Unidas Sobre Meio Ambiente e Desenvolvimento, ocorrida em junho de 1992, no Rio de Janeiro que reuniu 35 mil pessoas, entre elas 106 chefes de Estado. Este evento, considerado o maior fórum mundial já realizado sobre esta questão, aprofundou as discussões sobre o desenvolvimento sustentável e, apesar de alguns resultados negativos, a agenda do desenvolvimento sustentável ganhou enorme importância para a maioria dos países do mundo.

Na ECO 92, foram aprovados diversos documentos como a declaração do Rio,a convenção sobre mudanças climáticas, a declaração de princípios de florestas e a agenda 21. Esta agenda de trabalho para o novo século propunha por meio de um pacto entre o governo,setor produtivo e sociedade civil construir as bases de uma revolução cultural voltada para edificação de um novo modelo de sociedade.

Após a essa conferência, o conceito de desenvolvimento sustentável se disseminou mundialmente e planejadores públicos e privados passaram a construir seus projetos baseados na associação entre êxito econômico e preocupação sócio-ambiental. Para Negret:

O conceito de desenvolvimento sustentável propõe uma nova ordem econômica e social, em nível planetário, resultante de análises críticas e reflexivas das relações históricas entre os seres humanos e a terra. A sustentabilidade do desenvolvimento constitui o mais importante conceito surgido no debate sobre a questão ambiental, porque internalizou politicamente a ecologia como um instrumento de planejamento, abrindo novas perspectivas de desenvolvimento e progresso, além de recuperar valores humanos e a ética, destroçados por princípios absurdos da economia tradicional (NEGRET apud FERNANDES, 2004, p.57).

No final dos anos 80 e primórdios dos anos 90, período de intenso debate sobre esse paradigma alternativo de desenvolvimento, a economia mundial passou por uma grave crise e o Estado nacional-desenvolvimentista, na América Latina, bem como o Welfare State apresentaram profundos sinais de esgotamento em conseqüência da nova ordem globalizada. Diante disso, formou-se um consenso mundial em torno da valorização dos domínios territorializados e poderes locais.

\section{DESCENTRALIZAÇÃO DAS POLÍTICAS PÚBLICAS E PODER LOCAL}

As esferas subnacionais foram preteridas pela modernidade. O poder local era visto como um lugar marcado por características negativas como particularismos, relações pessoais, domínio tradicional e, por isso, condenado a obsolescência. O próprio Estado moderno se 
consolidou por meio da luta contra os poderes locais que eram rotulados de privados em oposição ao poder público estatal.

Mesmo o pensador clássico Aléxis de Tocqueville, grande defensor do papel do local na concretização da soberania popular, também diminuiu a importância dessa esfera de poder. Para o mesmo, a liberdade comunal se desenvolvia no interior de uma comunidade semibárbara, oposta à civilização e facilmente destruída.

No Brasil, não foi diferente, pois este poder foi pensado secularmente como um espaço da negatividade. O local era considerado o lugar de captura da esfera pública pela privada, do domínio do coronelismo e do patrimonialismo. O célebre jurista brasileiro Rui Barbosa, afirmava que o município não pertencia à esfera política, mas à esfera dos negócios privados.

Contudo, apesar desse legado histórico negativo b surgiu nas últimas décadas um movimento global de valorização dos poderes locais. Para CASTRO (1991), o atual consenso mundial produzido em torno da valorização do poder local é resultado da crise fiscal e tributária do Welfare State, nos países desenvolvidos e do Estado nacionaldesenvolvimentista na América Latina, ambas resultantes da globalização. Diante disso, organismos como a ONU e o Banco Mundial, passaram a recomendar as nações à concessão de mais autonomia aos entes federativos, como uma alternativa para a superação da crise do Estado-nação. Em contrapartida, os partidos de esquerda e os movimentos sociais no mundo inteiro também compartilham a tese da defesa da autonomia municipal como uma condição para consolidação da democracia, uma de suas bandeiras após a derrocada do socialismo.

Esse renascimento da positividade do local a partir dos anos 80 está por natureza ligado à questão da descentralização das políticas públicas. Apesar da modernidade haver desprestigiado as unidades subnacionais, a descentralização não é um tema recente na ciência política e já estava presente positivamente no pensamento dos clássicos. Montesquieu, por exemplo, no "Espírito das leis” defende uma concepção pioneira de redistribuição do poder como mecanismo de controle social.

Hoje, apesar de ser uma questão ambígua, a descentralização também se transformou num consenso mundial. Nas duas últimas décadas, os mais diferentes governos, dos mais distintos espectros ideológicos convergiram nas tentativas de descentralização. Na GrãBretanha aconteceu a descentralização privatizante do governo de Margareth Tatcher; Na França, a gestão Miterrand empreendeu uma ampla desconcentração administrativa. No Chile, predominou o modelo radical privatizante da gestão Pinochet.

No Brasil, a descentralização seguindo o movimento democrático mundial surgiu compulsoriamente e como uma alternativa para superação das crises econômica (fiscal) e política (legitimidade) por que passava o Estado brasileiro. Também aqui, esta é defendida de ângulos distintos pelos mais diversos setores políticos. Para a direita neoliberal, a implantação da mesma é uma eficiente estratégia de enxugamento da máquina administrativa e redução dos gastos públicos; através da seletividade no atendimento a demanda por serviços; já a esquerda reivindica-na como uma condição para a democracia, visto que a mesma aproxima o Estado do cidadão, viabilizando o controle social e tornando suscetível a universalização dos serviços públicos. 
Na verdade, o grande marco da descentralização brasileira foi à constituição de 1988. Desde o período colonial, os municípios estiveram submetidos à concentração de poderes administrativos e financeiros do poder central. Essa hipertrofia e dirigismo do executivo federal exacerbou-se no período dos governos militares pós 64, que, através da constituição autoritária de 1967, concentrou as políticas e a receita pública, deixando os municípios vulneráveis e na quase total dependência da tecnocracia dos gabinetes. No entanto, nos anos 89, o movimento internacional pró-descentralização associado às lutas dos movimentos sociais pela democracia no Brasil culminaram numa constituição que instaurou um novo pacto federativo e reconheceu o município como ente da federação.

Desse modo, os municípios ganharam mais autonomia político-administrativa e passaram a possuir incumbências que estiveram concentradas na esfera federal durante o regime militar. O município assumiu gradualmente a nova função de Welfare State, diante da crise do Estado nacional-desenvolvimentista que se tornou incapaz de satisfazer a crescente demanda por serviços públicos, sobretudo na área urbana.

\section{O NOVO PODER LOCAL E O DESENVOLVIMENTO SUSTENTÁVEL}

Desde a década de 30, com Getúlio Vargas, que o Estado nacional desenvolvimentista e centralizador ocupava o papel de principal coordenador do desenvolvimento sócioeconômico da nação. Nesse sentido, as políticas públicas fomentadoras do desenvolvimento estavam concentradas na esfera federal e os entes federativos eram simplesmente transmissores da sempre crescente demanda por serviços públicos. $\mathrm{Na}$ ditadura militar, políticas como as de habitação, saneamento básico, saúde, educação, assistência, geração de emprego e renda, turismo, além de outras, eram geridas pelo executivo federal, através de instituições como o BNH (Banco Nacional de Habitação), PLANASA (Plano Nacional de Saneamento), INAMPS (Instituto Nacional de Assistência Médica e Previdência Social), LBA (Legião Brasileira de Assistência) e EMBRATUR (Instituto Brasileiro de Turismo). Embora os problemas fossem locais, suas soluções eram discutidas nos gabinetes do Distrito Federal. No entanto, a partir dos anos 80, com a crise fiscal do Estado nacional desenvolvimentista e o surgimento do neoliberalismo, a União perdeu sua capacidade de financiamento e gerenciamento das políticas do desenvolvimento. Nesse sentido, estas ações foram sendo repassadas para as instâncias subnacionais, principalmente para as cidades, que se tornaram protagonistas do desenvolvimento sócio-econômico e político da nação.

Diante dessa redefinição sofrida pelo poder local, os municípios deixam de ser meros executores de pequenos serviços públicos urbanos como recolhimento do lixo, manutenção de creches, dentre outros. A crise fiscal do Estado nacional, as reivindicações dos movimentos sociais pró-descentralização e a explosão urbana provocando o agravamento dos problemas sócio-econômicos e ambientais urbanos fez as cidades assumirem o papel de principais promotoras e coordenadoras do desenvolvimento urbano, através do planejamento da gestão dos principais serviços públicos de interesse local. No dizer de Dowbor:

É do resgate da raiz da polis da política que dependerá a nossa possibilidade de ultrapassar uma fase em que as políticas urbanas são cortadas em fatias setoriais desarticuladas, onde a ocupação do espaço se dá no processo selvagem da especulação, da corrupção e da violência, onde o uso predatório dos recursos 
naturais liquida a cobertura vegetal gerando enchentes e caos climáticos, onde os rios inundados de produtos químicos colocam em risco nosso futuro (1998 p.374).

\section{DESENVOLVIMENTO SUSTENTÁVEL NO LOCAL E TURISMO}

Nesta nova fase vivida pelo poder local, as cidades estão se tornando gestoras de políticas como as de transporte, educação, saúde, meio ambiente, assistência social, turismo dentre outras.

No caso do turismo esse processo teve seu advento com o Plano Nacional de Municipalização do Turismo (PNMT), que começou a ser implementado em meados dos anos 90. Esse plano, apesar de não haver atingido todos os seus objetivos, disseminou a conscientização sobre o papel dos municípios no desenvolvimento da atividade turística. Pois é no local que estão os recursos, produtos, serviços, infra-estrutura e equipamentos turísticos e, em última instância é este ente federativo que sofre os impactos positivos e negativos provocados pela pratica desta atividade. Para Dias:

A vinculação entre o local e o global é claramente percebida no turismo, pois quando falamos de fluxos turísticos internacionais, os impactos que se observam ocorrem, essencialmente no nível local, onde se localizam os atrativos que estão sob o controle territorial de alguma administração (2003 p.152-53).

Mas o desenvolvimento turístico local deve ocorrer com base nos princípios da sustentabilidade. Pois apesar de ser denominada por alguns de "indústria sem chaminé”, o turismo tem ao longo de sua história produzido em algumas destinos impactos bastante negativos como a destruição de tradições e identidades culturais, o aumento da prostituição e do tráfico de drogas, e a degradação da natureza. Nesse sentido, As políticas implementadas neste setor devem levar em consideração a conservação e valorização do patrimônio natural e cultural local, a distribuição eqüitativa dos benefícios econômicos do turismo e a satisfação do turista. Conforme a Organização Mundial do Turismo (OMT), o turístico sustentável é aquele que:

Atende as necessidades dos turistas atuais e das regiões receptoras e ao mesmo tempo protege e fomenta as oportunidades para o turismo futuro. Concebe-se como um caminho para a gestão de todos os recursos de forma que possam satisfazer-se as necessidades econômicas, sociais e estéticas, respeitando ao mesmo tempo a integridade cultural, os processos ecológicos essenciais, a diversidade biológica e os sistemas que sustentam a vida (OMT, 1993, p.24).

A implementação de políticas públicas que se baseiam nas várias dimensões do desenvolvimento sustentável são decisivas.

Desse modo, um dos caminhos para a sustentabilidade das políticas locais de turismo passa pela questão da intersetorialidade. Por muito tempo as políticas públicas em geral estiveram totalmente fragmentadas e desarticuladas, se tornando incapazes de solucionar os problemas mais complexos. O turismo é um sistema sócio-econômico bastante complexo e sua sustentabilidade depende de ações nas áreas da saúde, saneamento básico, educação, meio ambiente, cultura, ou seja, as demais políticas públicas locais devem estar articuladas com as de turismo objetivando criar um lugar agradável para nativos e turistas, condição sine quo non para desenvolver esta atividade sustentavelmente. 
Um dos grandes obstáculos ao desenvolvimento no atual contexto de reestruturação produtiva tem sido o desemprego. Diante disso, o turismo de base local se constitui numa importante estratégia de superação desse dilema, visto que é capaz de gerar emprego e renda com baixos investimentos, além de aumentar a captação de divisas para o local e estimular o desenvolvimento de outras atividades econômicas. Mas esse fomento da economia mediante a atividade turística, precisa ser sustentável e, por isso, deve se basear na preservação dos recursos culturais e naturais e no protagonismo econômico dos atores locais.

O uso e ocupação predatória do solo tem se constituído muitas vezes num empecilho ao desenvolvimento sustentável local. Isto é muito comum nos municípios com vocação turística que se tornam vítimas da especulação imobiliária selvagem capitalista. Uma maneira de evitar esta apropriação capitalista degradante do espaço, que expulsa a população nativa do seu habitat é por meio da realização do planejamento turístico integrado, sustentável e participativo em que os planos diretores, códigos de postura e outros documentos que regulamentam o uso e ocupação do solo representem os anseios da população e estejam a serviço do desenvolvimento sócio-econômico do lugar.

As parcerias municipais ou consórcios se constituem numa eficiente estratégia de desenvolvimento. Municípios com vocação turística podem criar pólos e roteiros turísticos para oferecem diversos produtos e serviços turísticos competitivos e para captarem investimentos públicos e privados. O atual programa de regionalização do turismo é emblemático nesse aspecto e propõe a construção de planos de desenvolvimento regionais sustentáveis, além de roteiros turísticos integrados.

Outra dimensão relevante na perspectiva da construção do desenvolvimento é a questão da participação. A criação de conselhos para gerenciar as ações do setor turístico compostos por representantes do poder municipal, ONGs, empresários e outros setores é fundamental, pois o desenvolvimento sustentável possui uma dimensão política, que se materializa na expansão e aperfeiçoamento dos mecanismos democráticos e participativos. O poder local é, nesse sentido, uma esfera privilegiada para efetivação da sustentabilidade política.

\section{CONSIDERAÇÕES FINAIS}

Diante disso, são muitos os desafios propostos a construção do desenvolvimento local sustentável. Todavia, as mudanças paradigmáticas nas esferas políticas e econômicas em curso no mundo inteiro e no Brasil propõem caminhos viáveis para implantação desse modelo capaz de proporcionar avanços na relação dos homens com a natureza, nas relações sociais e no fazer político. Nesse contexto, nos municípios com vocação turística, esta atividade se constitui numa alternativa promissora para implantação de políticas de desenvolvimento sustentável capazes de desenvolver integralmente estas localidades.

\section{REFERÊNCIAS BIBLIOGRÁFICAS}

1. CAMARGO, Ana Luiza De Brasil. Desenvolvimento sustentável: Dimensões e desafios. Campinas: Papirus,2003.(coleção papirus educação) 
2. CASTRO, Maria Helena Guimarães. Descentralização e política social no Brasil: $\mathbf{O}$ desafio dos anos 90. In: Revista espaço e debate. São Paulo: CEDEC, ano XI, n ${ }^{\circ} 32$ p.80-87,1991.

3. CONSELHO MUNDIAL PARA O MEIO AMBIENTE E DESENVOLVIMENTO. (CMMAD). Nosso futuro comum. 2ed. Rio de Janeiro: FGV, 1991.

4. DIAS, Reinaldo. Política e desenvolvimento do turismo no Brasil. São Paulo: Atlas, 2003.

5. DOWBOR, Ladislau. A reprodução social: Propostas para uma gestão descentralizada. Petrópolis: vozes, 1998.

6. ENGELS, Friedrich. A humanização do Macaco pelo trabalho: dialética da natureza. 3ed. Rio de Janeiro: paz e terra, 1979.

7. FERNANDES, Cláudio Tadeu Cardoso. Desenvolvimento sustentável: afinal de contas, o que vem a ser isto? In: Revista universitas de geografia. Brasília: Centro universitário de Brasília, nº 01, p.50-57, 2004.

8. ORGANIZAÇÃO MUNDIAL DO TURISMO (OMT). Guia de desenvolvimento do turismo sustentável. Trad. Sandra Netz. Porto Alegre: Bookman,2003.

9. SACHS, Ignacy. Estratégias de transição para o século XXI: Desenvolvimento e meio ambiente. São Paulo: Studio nobel/fundap,1993.

10. SILVA, Edna Lúcia; MENEZES, Estera Muszkat. Metodologia da pesquisa e elaboração de dissertação. 2ed. Florianópolis: Laboratório de ensino à distância da UFSC, 2001. 